\title{
Should computed chest tomography be recommended in the medical certification of professional divers? A report of three cases with pulmonary air cysts
}

\author{
A S Toklu, E Kiyan, S Aktas, M Cimsit
}

Pulmonary barotrauma (PBT) is a recognised risk of compressed gas diving. Any reason that causes air trapping in the lung during ascent may cause PBT by increasing intrapulmonary pressure. Chest $x$ ray examination is mandatory for medical certification of the professional divers in many countries, but pulmonary air trapping lesions such as an air cyst in the lungs cannot always be detected by plain chest $x$ ray examination. Computed tomography (CT) is a reliable, but expensive measure for detecting pulmonary abnormalities in divers. Three cases with pulmonary air cysts are reported in which air cysts were invisible on the $x$ ray pictures, but well defined by CT. It is impractical and not cost effective to perform CT for medical certification of all divers, but it can be an option to recommend $\mathrm{CT}$ once during the initial examination of the candidates for professional diving, especially if there is a history of predisposing factors, such as smoking or pulmonary infections.

$\mathrm{T}$ here are several medical standards in different countries for initial or periodic certification of professional divers. These standards are slightly different than each other and established to ensure that only fit candidates receive or renew their dive certification. Chest $x$ ray examination is mandatory in many countries, but the intervals vary from annual to every five years. ${ }^{1}$ One of the purposes of the chest $x$ ray examination is to check the presence of lung cysts, emphysematous blebs, or bullae, which might predispose pulmonary barotraumas (PBT) and preclude diving.

PBT is a risk for divers who breathe compressed gas while immersed at pressure. On ascent the gas in the air containing cavities of the body will expand, in accordance with Boyle's Law, since environmental pressure is reduced during ascent. A volume of gas at $10 \mathrm{~m}$, where the pressure is 2 atmospheres absolute (ATA), will double at the surface since the pressure is decreased to 1 ATA. During ascent, the expanded gas in the lungs must be exhaled to prevent pulmonary overinflation. Any reason that causes air trapping in the lungs or breath holding during ascent may cause PBT by increasing intrapulmonary pressure. The air trapped in the lung can rupture the alveoli by expanding during decompression. Thus, the gas in the ruptured alveoli might escape to the interstitial space, track along perivascular sheaths, and cause mediastinal emphysema, pneumothorax, or subcutaneous emphysema. If the gas enters the pulmonary circulation via torn vessels next to the ruptured alveoli, it goes to the left heart and causes arterial gas embolism (AGE). AGE is the most dangerous complication of pulmonary barotrauma and is a major cause of mortality in diving. ${ }^{2}$ In a study of fatal diving accidents, $31 \%$ of the deaths were attributed to AGE. ${ }^{3}$
Subpleural emphysematous blebs or air cysts may predispose to PBT since they may cause air trapping. ${ }^{4}$ Existence of air trapping lesions in the lung is therefore a reason for disqualifying divers. ${ }^{5}$ These lesions might be missed on plain chest $x$ ray examination, but can be well defined by chest computed tomography $(\mathrm{CT}) .^{6-8}$ In this paper, three cases with pulmonary abnormalities are reported in which pulmonary air trapping lesions probably expanded during ascent, and resulted in PBT. The lesions were verified by high resolution computed tomography (HRCT) in all cases whereas the abnormalities could not be detected on plain chest $x$ ray pictures.

The cases reported in this paper were referred to the Department of Underwater and Hyperbaric Medicine, Istanbul Faculty of Medicine; CT (Siemens Somatom Plus) examinations were performed with $1.5 \mathrm{~mm}$ slice thickness HRCT scans at the Radiology Department of the Faculty.

\section{CASE 1}

A 56 year old male professional underwater photographer with 15 years of diving experience; smoker (20 cigarettes a day for 20 years).

He dived to $35 \mathrm{~m}$ and noticed he was out of air after 35 minutes at the bottom. He started ascending rapidly since he was alone. He experienced no problems when he surfaced. The next day he felt discomfort while breathing during his dive to $20 \mathrm{~m}$ and interrupted the dive. He had a pain in his chest and was dyspnoeic when he arrived at the surface. He did not dive for 12 days as the pain persisted. He underwent medical examination.

A pneumothorax on the left side was detected by chest $x$ ray examination (fig 1). A large bulla, located on the apical part of the left lung and in connection with pneumothorax, was detected on HRCT (fig 2). Normobaric 100\% oxygen was administered for four hours a day for six days; the pneumothorax had subsided at control chest $x$ ray examination. He was excluded from diving.

\section{CASE 2}

A 36 year old male professional diver with 15 years of diving experience; smoker (25-30 cigarettes a day for 10 years).

He performed a dive to $38 \mathrm{~m}$ with 29 minutes bottom time, and obeyed decompression stops according to US Navy Standard Air Decompression Table as if he had dived 140 feet $(42.6 \mathrm{~m})$. He felt pins and needles in his right arm while he was in water at the $3 \mathrm{~m}$ decompression stop. He did not feel his right arm and could hardly stand with assistance when he

Abbreviations: AGE, arterial gas embolism; ATA, atmospheres absolute; $\mathrm{CT}$, computed tomography; DCS, doubtful decompression sickness; HRCT, high resolution computed tomography; PBT, pulmonary barotrauma 


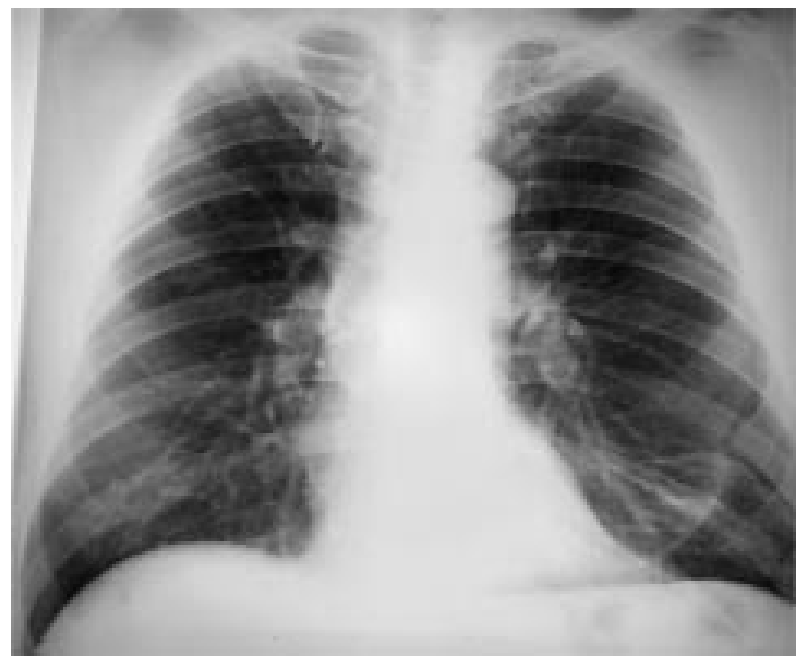

Figure 1 Case 1: $x$ ray picture.

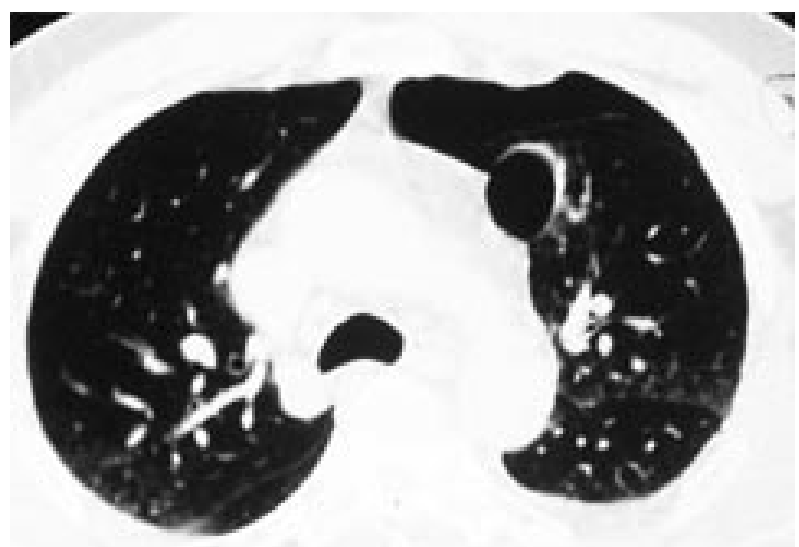

Figure 2 Case 1: HRCT scan.

came to the platform, after completing his decompression stop. After a few minutes he collapsed with hemiplegia on the right side, but there was no alteration of consciousness. There was no cough or any problem with breathing. The ascent was uneventful; the rate was about $10 \mathrm{~m} / \mathrm{min}$. The dive was his 62nd dive with similar profiles during an underwater pipeline installation. He had had no problems during his previous dives. Immediate recompression therapy was performed in 10 minutes according to US Navy Treatment Table 6. The symptoms started to decrease in the first few minutes and disappeared completely in the first 20 minutes at a depth of 60 feet in the recompression chamber.

Physical examination revealed no pathological findings at the end of treatment. Pulmonary barotrauma was suspected rather than decompression sickness. Investigation was performed for a possible precipitating factor for PBT in the lungs. HRCT of the chest showed an azygos lobe on the right side and multiple air cysts bilaterally (fig 3), which were not visible on the chest $x$ ray pictures (fig 4). He was excluded from diving.

\section{CASE 3}

A 25 year old male professional diver with six months diving experience.

He performed a scuba dive, and spent 35 minutes at 9-10 $\mathrm{m}$ after staying one minute at his maximum depth of $17 \mathrm{~m}$. He surfaced slowly after spending three minutes at $5 \mathrm{~m}$. He was dizzy and complained of visual disturbances, with numbness in the right leg, a few minutes after surfacing. The symptoms

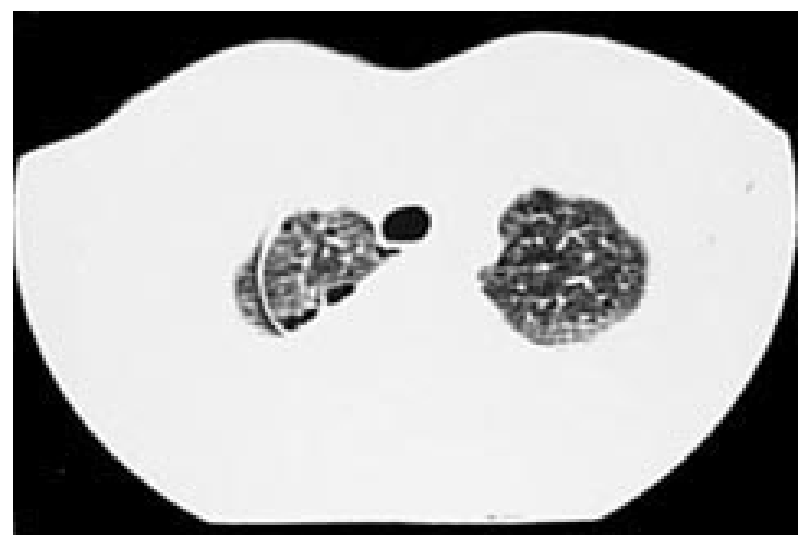

Figure 3 Case 2: HRCT scan.

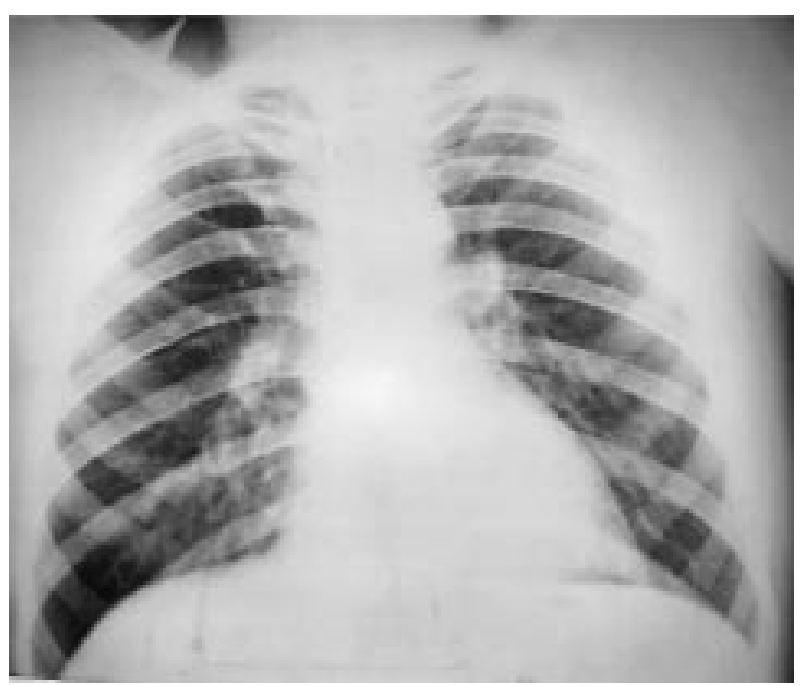

Figure 4 Case 2: $x$ ray picture.

disappeared spontaneously within 10 minutes. He performed another dive with a similar profile the next day and had no problems. Three days later he performed a dive and spent 14 minutes at $37 \mathrm{~m}$. He ascended slowly to $1-2 \mathrm{~m}$ in 10 minutes uneventfully, but did not remember surfacing from 1 to $2 \mathrm{~m}$. He was unconscious at the surface. He became conscious 30 minutes after surfacing.

Physical examination revealed motor and sensory disturbances of the lower extremities when he reached the hyperbaric facility 48 hours later. He underwent repetitive recompression therapies to achieve complete recovery. HRCT of the chest revealed a small bleb on the upper part of the right lung, which could not be detected by chest $x$ ray examination. He was excluded from diving.

\section{DISCUSSION}

Pulmonary barotrauma is a recognised risk of compressed gas diving, which occurs mostly among inexperienced divers, as they might hold their breath during ascent, because of panic. ${ }^{9}{ }^{10}$ Studies of accidents during submarine escape training have also revealed that the incidence of PBT among initial trainees is higher than among requalifiers. ${ }^{11}$ PBT occurs during ascent when there is either breath holding or regional gas trapping, resulting in an increase in intrapulmonary pressure. ${ }^{12}$ Some reports have stated that transpulmonic pressures of $60-70 \mathrm{~mm} \mathrm{Hg}$ are sufficient to cause rupture of alveolar septa and allow escape of gas into interstitial spaces. ${ }^{13}{ }^{14}$

The onset of clinical symptoms of AGE is usually within the first minutes of surfacing. Leitch et al reported that onset time 
of symptoms after surfacing was less than five minutes in 97\% of their 117 AGE cases. ${ }^{15}$ In two of our cases the symptoms appeared while the divers were still in water.

In the first case the diver made rapid ascent in a dive but did not have any symptoms afterwards. He had symptoms after the second dive he performed on the next day. It is known that some PBT cases might be asymptomatic. It is more likely that an asymptomatic PBT occurred during the first dive, which became symptomatic when the diver dived on the next day. Probably the pneumothorax, which developed during the first dive, became symptomatic during the second dive.

Involvement of the central nervous system is common in cases of pulmonary barotrauma. ${ }^{16}$ In two of our cases there were symptoms that might be related to central nervous system involvement. A pneumothorax was evident in the dive who had no neurological symptoms.

Some predisposing factors, such as pulmonary infections or smoking, may increase the likelihood of emphysematous changes in the lung. ${ }^{17-19}$ There was a history of smoking in two of our cases, which might have contributed to the formation of bullous lesions in the divers' lungs. It is especially important to investigate such lesions by HRCT, if the divers have history of smoking or lung infection.

It is evident that not all emphysematous bullae are visible on plain chest $x$ ray examination, but can be seen clearly on CT scans. ${ }^{6-8} 2021$ Air cysts or blebs were detected in all of our cases on HRCT scans, but the lesions were not visible on the $x$ ray pictures. A pneumothorax was clear on the chest $x$ ray picture in case 1 , but there was no image indicating a bulla.

Existence of subpleural blebs, pulmonary air cysts, or an emphysematous bulla should disqualify a subject from compressed air diving, as they may facilitate PBT to occur. There have been several reports where preexisting medical condition predisposed to PBT. ${ }^{1522}$ Aktas at al reported four cases of PBT in which pulmonary lesions were detected on CT scan. They suggested that in doubtful decompression sickness (DCS) cases, CT scanning of the chest must be performed not only for differential diagnosis but also for disqualification. ${ }^{23}$

We conclude that screening the divers by chest $x$ ray examination is not sufficient to detect all possible air cysts in the lung and may be excluded from the routine examination. The reliable measure for detecting pulmonary abnormalities during medical assessment of the divers is HRCT. However, it is impractical to perform CT for both recreational and professional divers, because of its cost and lack of facilities. It can, however, be a good decision to recommend performing it only during the initial examination of the professional divers, especially if there is a history of predisposing factors such as smoking or pulmonary infections.

\section{Authors' affiliations}

A S Toklu, S Aktas, M Cimsit, Istanbul University, Istanbul Faculty of Medicine, Department of Underwater and Hyperbaric Medicine, Istanbul, Turkey

E Kiyan, Istanbul University, Istanbul Faculty of Medicine, Department of Respiratory Disease, Istanbul, Turkey
Correspondence to: Dr A S Toklu, Deniz ve Sualti Hekimligi AD, Istanbul Tip Fakultesi, Capa Istanbul 34390, Turkey; akin@toklu.net

Accepted 11 October 2002

\section{REFERENCES}

1 Örnhagen $\mathbf{H}$. What are the international differences of potential significance? In: Elliott DH, ed. Medical assessment of fitness to dive. Surrey: Biomedical Seminars, 1995:24-31.

2 Dick AP, Massey EW. Neurologic presentation of DCS and air embolism in sport divers. Neurology 1985:35:667-71.

3 Schench HV, McAniff JJ. United States underwater fatality statistics 1972. Report no. URI-73-8. NOAA grant no. 4-3-159-31. Kingston, RI: University of Rhode Island, 1972.

4 Edmonds C. Pulmonary barotrauma. In: Edmonds C, Lowry C, Pennefather J, eds. Diving and subaquatic medicine, 3rd edn. Sydney, Australia: Butterworth-Heinemann Medical, 1992:95-115.

5 Mebane GY, McLver NKI. Fitness to dive. In: Bennett P, Elliott DH, eds. The physiology and medicine of diving, 4th edn. London: WB Saunders, 1993:53-76.

6 Reuter M, Ketzlaff K, Warninghoff V, et al. Computed tomography of the chest in diving-related pulmonary barotrauma. Br J Radiol 1997;70:440-5

7 Lesur O, Delorme N, Fromaget JM, et al. Computed tomography in the etiologic assessment of idiopatic spontaneous pneumothorax. Chest 1990;98:341-7.

8 Tetzlaff $\mathbf{K}$, Reuter $M$, Leplow $B$, et al. Risk factors for pulmonary barotraumas in divers. Chest 1997; 1 12:654-9

9 Murrison AW, Lacey EJ, Restler M, et al. Ten years of diving-related illness in the royal Navy. J Soc Occup Med 1991:41:217-19.

10 Dovenbarger J. Report on diving accidents and fatalities. Durham, NC: Divers Alert Network, 1994.

11 Benton PJ, Woodfine JD, Francis TJR. A review of spirometry and UK submarine escape training tank incidents (1954-1993) using objective diagnostic criteria. Report R94011. Alverstoke, UK: Institute of Naval Medicine, 1994.

12 Mellem H, Emhiellen S, Horgen O. Pulmonary barotrauma and arteriel gas embolism caused by an emphysematous bulla in a SCUBA diver. Aviat Space Environ Med 1990;6:559-62.

13 Malhotra MS, Wright HC. Arterial air embolism during decompression and its prevention. Proc R Soc Lond B 1960;154:418-27.

14 Malhotra MS, Wright HC. The effects of a raised intrapulmonary pressure on the lungs of fresch unchilled cadavers. J Pathol Bacteriol 1961:82:198-202.

15 Leitch DR, Green MB. Pulmonary barotrauma in divers and the treatment of cerebral arteriel gas embolism. Aviat Space Environ Med 1986;57:931-8.

16 Elliott DH, Harrison JAB, Barnard EEP. Clinical and radiological features of 88 cases of decompression barotrauma. Symposium on underwater physiology VI. Bethesda, MD: Federation of American Societies for Experimental Biology, 1978:527-35.

17 Stern EJ, Webb WR, Weinacker A, et al. Idiopatic giant bullous emphysema (vanishing lung syndrome): imaging findings in nine patients. AJR Am J Roentgenol 1994;162:279-82.

18 Ohtsuka Y, Homma Y, Ukita H, et al. Clinical characteristic of idiopathic interstitial pneumonia (IIP) with bullae. Intern Med 1994;33:6-9.

19 Martin KJ, Robin PS, Douglas M, et al. Large lung bullae in marijuana smokers. Thorax 2000;55:340-2.

20 Fiore D, Biondetti PR, Sartori F, et al. The role of computed tomography in the evaluation of bullous lung disease. J Comput Assist Tomogr 1982;6:105-8

21 Mitlehner W, Friedrich M, Dissmann W. Value of computer tomography in the detection of bullae and blebs in patients with primary spontaneous pneumothorax. Respiration 1992;59:221-7

22 Liebow AA, Stark JE, Vogel J, et al. Inrapulmonary air trapping in submarine escape training casualties. United States Armed Forces Medical Journal 1959;10:265-89.

23 Aktas S, Aydin S, Nogay HA, et al. Pulmonary CT scanning should be considered in doubtful DCS to eliminate pulmonary gas embolism. Proceedings of XIXth EUBS. Trondheim, Norway: 1993:105-8. 